\title{
Acute kidney injury among nonagenarians in Jordan: a retrospective case-control study
}

This article was published in the following Dove Press journal: International Journal of Nephrology and Renovascular Disease

\author{
Sameeha A Alshelleh' \\ Ashraf O Oweis ${ }^{2}$ \\ Karem H Alzoubi ${ }^{3}$ \\ 'Division of Nephrology, Department \\ of Medicine, The University of \\ Jordan, Amman, Jordan; ${ }^{2}$ Division of \\ Nephrology, Department of Medicine, \\ Jordan University of Science and \\ Technology, Irbid, Jordan; ${ }^{3}$ Department \\ of Clinical Pharmacy, Faculty of \\ Pharmacy, Jordan University of \\ Science and Technology, Irbid, Jordan
}

Correspondence: Sameeha A Alshelleh Division of Nephrology, Department of Medicine, The University of Jordan, Amman, Jordan

Tel +962799691928

Email sameehaaalshelleh3@gmail.com
Background: Improvements in health care systems worldwide have had notable effects on the life expectancy of older individuals. As a result, nonagenarians are emerging as a separate age group with distinct health care needs. The aim of this study was to evaluate the incidence of acute kidney injury (AKI), the mortality rates, and length of in-hospital stay among nonagenarians. Methods: This is a retrospective case-control chart review of patients of age 90 years and above who were admitted to hospital. Patients with Stage I, II, or III chronic kidney disease were included in the analysis. The incidence of AKI was determined using data from the Acute Kidney Injury Network (AKIN) classification. Primary outcome variables included length of in-hospital stay and mortality rates.

Results: Of the 253 patients who were included in the study, the mean age was 91.5 years, 61 of the patients (25.9\%) developed AKI, and 41 patients (66.1\%) were in Stage I AKI according to AKIN criteria. Fifty-seven patients died during the study period; $57.9 \%$ of those patients had AKI. Hospital stay was longer in patients with AKI with a mean length of stay of 8.1 days. Congestive heart failure, cancer, and use of non-steroidal anti-inflammatory drugs were the main risk factors for AKI among those patients.

Conclusion: AKI is common in nonagenarians. It was associated with increased length of hospital stays and increased risk for mortality.

Keywords: acute kidney injury, elderly, geriatric, outcomes

\section{Introduction}

Medical improvements, including the introduction of new medications, medical procedures, and treatment guidelines, lead to a longer lifespan. ${ }^{1}$ Over the past several decades, there have been marked changes in health care systems contributing to the large proportion of individuals over the age of 75 years within the global population. Currently, within many medical fields, the issue of most concern is how much current medical practice and recommendations are fitting the specific health care needs of older individuals, such as octogenarians, nonagenarians, and other older individuals. Questions remain on how current practices are affecting rates of morbidity and survival. ${ }^{2-4}$

With aging, different physiological and functional changes occur in kidneys, such as reduction in glomerular filtration rate (GFR), loss of cortical volume, and nephrosclerosis. ${ }^{5,6}$ With many individuals reaching the age of 75 years or above, the number of hospitalized geriatric patients is increasing, with many of those patients presenting with acute kidney injury (AKI). ${ }^{7,8}$ Geriatric patients have increased risk of AKI because of aging, multiple comorbidities, ${ }^{5,9}$ and polypharmacy use. ${ }^{10-13}$ The aim of this study 
was to evaluate the incidence of AKI, the mortality rates, and length of in-hospital stay among nonagenarians in Jordan.

\section{Methods}

\section{Patient selection and data collection}

The Strengthening the Reporting of Observational Studies in Epidemiology official reporting guidelines were followed to ensure proper and standard reporting of results from observational studies in epidemiology (cohort, case-control studies, and cross-sectional studies). All nonagenarians admitted to the medical ward of the main tertiary referral teaching hospital in north of Jordan between January 2010 and December 2013 were retrospectively evaluated. All patients who were admitted from the emergency room or outpatient clinic and had at least 1 year of follow-up were included in the study (the mean time of follow-up was 12.3 months; \pm 4.2 ). The first admission of each patient was analyzed to determine if the patient had more than one admission. Only patients with hospital-acquired AKI were considered in this study.

Demographic data, including age, gender, comorbidities, cause of admission, current medications, and laboratory data, were extracted from patients' electronic records. Regular use of on non-steroidal anti-inflammatory medications (NSAIDs) was defined as at least 2 times/week for 3 months. Angiotensin-converting enzyme inhibitor and angiotensin receptor blockers' use was considered when it exceeded 3 months of regular use. Exclusion criteria were age $<90$ or $>100$ years, Stages IV or V chronic kidney disease (CKD), and chronic dialysis requirement. Patients without baseline serum creatinine were also excluded from the study. AKI was defined using the Acute Kidney Injury Network (AKIN) classification. ${ }^{14}$ GFR was calculated using the Chronic Kidney Disease Epidemiology Collaboration equation, and contrast exposure was defined as intravenous contrast administration within 1 week of AKI onset. The study was approved by the Institutional Research Board (IRB) of King Abdullah University Hospital, Irbid, Jordan. All procedures performed in the study were in accordance with the 1964 Helsinki declaration and its later amendments. Because of the retrospective study design, the requirement for patient consent was waived as per IRB desertion. Patients' data were kept confidential, and no patients' identifier was included in data files handled for the purposes of this study.

Statistical analyses were performed using STATA/MP, version 14.0 (StataCorp LLC, College Station, TX, USA). Data were described using mean and \pm SD for continuous variables and percentages for categorical variables. Patients were divided into two groups: patients with and without AKI. The differences between the mean of continuous variables among the two groups were tested using independent $t$-tests. Pearson's chi-squared test was used to compare the incidence rates of AKI according to the distribution of demographic, clinical, and relevant patient characteristics between the two groups. Cox proportional hazard model was used to assess the effect of different covariates on outcomes. Multivariate analysis was carried out based on significant factors in univariate analysis plus those factors considered clinically significant by consultant nephrologist.

\section{Results}

\section{Patient characteristics}

Of the 283 nonagenarians admitted during the study period, 48 were excluded due to being classified as CKD Stages $\mathrm{IV}$ and $\mathrm{V}$ or requirements for chronic dialysis. In the 235 remaining patients, the mean age was 91.5 years, $14.5 \%$ were diabetic, $17.5 \%$ had hypertension, and $3.4 \%$ were chronically on NSAIDs. Baseline characteristics are presented in Table 1.

The most common causes of admission were acute coronary syndrome (ACS; 14.2\%) and uncontrolled diabetes mellitus (15.4\%). Other causes for admission were nervous system disease most frequently manifested as stroke (ischemic, 9.1\%; hemorrhagic, 1.9\%) and infection (17.0\%), most commonly urinary tract infection $(7.7 \%)$, pneumonia $(2.4 \%)$, and other infections $(6.9 \%)$. Injury secondary to a fall accounted for $5.3 \%$ of admissions. Deep vein thrombosis was a cause in $3.4 \%$ of the admissions. Table 2 shows the most common causes of admission based on AKI status.

Table I Baseline characteristics of all patients included in the study

\begin{tabular}{|l|l|}
\hline Variable & N (\%) \\
\hline Gender & \\
\hline Male & $\mathrm{I} 23(52.3)$ \\
\hline Female & $\mathrm{I} I 2(47.7)$ \\
\hline Comorbidities & \\
\hline Diabetes mellitus & $34(\mathrm{I} 4.5)$ \\
\hline Hypertension & $4 \mathrm{I}(\mathrm{I} 7.5)$ \\
\hline Coronary artery disease & $44(18.7)$ \\
\hline Congestive heart failure & $20(8.5)$ \\
\hline Cerebral vascular accident & $25(10.6)$ \\
\hline Peripheral vascular disease & $53(22.6)$ \\
\hline Cancer (solid tumors) & $14(5.9)$ \\
\hline Medications & \\
\hline Angiotensin-converting enzyme inhibitor & $80(34.0)$ \\
\hline Angiotensin receptor blockers & $38(\mathrm{I} 6.2)$ \\
\hline Non-steroidal anti-inflammatory drugs & $8(3.4)$ \\
\hline Contrast & $46(19.6)$ \\
\hline Baseline creatinine, mean \pm SD ( $\mu$ mol/L) & $134.9(105.3)$ \\
\hline
\end{tabular}




\section{Incidence and outcome of AKI}

The AKI developed 2-5 days from admission. AKI was diagnosed in 61 patients (25.9\%). Of these cases, $66.1 \%$ had Stage I disease whereas Stage II and Stage III disease were present in $12.9 \%$ and $21.0 \%$, respectively. A comparison of baseline characteristics in both groups (Table 3) revealed that patients with AKI were associated with congestive heart failure $(P=0.001)$, cancer $(P=0.001)$, or being regularly on NSAIDs $(P=0.01)$. Exposure to intravenous contrast material $(P=0.69)$ or being on angiotensin-converting enzyme inhibitors or angiotensin receptor blockers $(P=0.70)$ were not different among AKI vs non-AKI patients. The hospital stay was longer in the AKI than in the non-AKI group; 8.1 days $( \pm 7.7)$ vs 4.2 days $( \pm 6.1)$, respectively $(P=0.0001)$. By the end of the 1-year follow-up, the mean serum creatinine was $157.3 \mu \mathrm{mol} / \mathrm{L}( \pm 104.0)$ for the AKI group, mean estimated glomerular filtration rate $53.6 \mathrm{~mL} / \mathrm{min}( \pm 53.8)$ vs 120.3 $\mu \mathrm{mol} / \mathrm{L}( \pm 74.6)$ for the non-AKI group and $61.8 \mathrm{~mL} / \mathrm{min}$ $( \pm 31.9)$ with a $P$-value of 0.02 . Of the 57 patients $(24.5 \%)$ who died before discharge, 33 (57.9\%) developed AKI. In the patients who developed AKI, 28 (11.9\%) of patients underwent dialysis. Using Cox proportional hazard model, hypertension increased the risk of mortality by 4.2 times, cancer by 1.7 times, while other factors including causes of admission did not (Table 4).

\section{Length of stay}

The hospital stay was longer in the AKI than in the nonAKI group; 8.1 days $( \pm 7.7)$ vs 4.2 days $( \pm 6.1)$, respectively $(P=0.0001)$. To study the effect of the cause of admission on the length of stay, patients were divided into two groups based on length of stay; $<5$ and $\geq 5$ days. The 5 days were chosen as a cutoff because the overall mean length of stay was 5.1 days.

Uncontrolled DM and CNS cause of admission had a statistically significant shorter length of stay $P=0.002$ and $P=0.004$, respectively, than other causes.

\section{Discussion}

Due to the impact of aging on the global health care system and the associated increase in comorbidities and mortality, methods to delay aging is now becoming a focus in many research endeavors. ${ }^{15}$ There is still room for improvement in the health care system that can be directed at the worldwide increase in population of older individuals. ${ }^{1,16}$

Table 4 The risk of mortality among nonagenarians with AK using Cox proportional HR

\begin{tabular}{|l|l|l|l|}
\hline Variable & HR & $\mathbf{9 5 \%} \mathbf{C l}$ & $\boldsymbol{P}$-value \\
\hline Age & 0.54 & $0.18-1.6$ & 0.29 \\
\hline Diabetes mellitus & 0.47 & $0.68-3.7$ & 0.72 \\
\hline Hypertension & 4.2 & $0.17-10.3$ & 0.37 \\
\hline Congestive heart failure & 0.14 & $0.10-2.0$ & 0.15 \\
\hline Cancer & 1.7 & $0.9-13.9$ & 0.83 \\
\hline
\end{tabular}

Abbreviation: AKI, acute kidney injury.

Table 2 The most common causes of admission based on AK status

\begin{tabular}{|l|l|l|l|}
\hline Variable & AKI (+) & AKI (-) & $\boldsymbol{P}$-value \\
\hline Acute coronary syndrome & $\mathbf{I 6}(6.3 \%)$ & $20(7.9 \%)$ & 0.21 \\
\hline Uncontrolled diabetes mellitus & $4(5.5 \%)$ & $25(9.9 \%)$ & 0.1 \\
\hline Stroke & $10(3.9 \%)$ & $18(7.1 \%)$ & 0.23 \\
\hline $\begin{array}{l}\text { Infections (urinary tract } \\
\text { infection, pneumonia, and } \\
\text { other infections) }\end{array}$ & $9(3.6 \%)$ & $34(13.4 \%)$ & 0.37 \\
\hline
\end{tabular}

Abbreviation: AKI, acute kidney injury.

Table 3 Baseline characteristics for nonagenarians based on AKI status

\begin{tabular}{|c|c|c|c|}
\hline Variable & AKI (+) & AKI (-) & $P$-value \\
\hline \multicolumn{4}{|l|}{ Comorbidities } \\
\hline Diabetes mellitus & $12(19.7 \%)$ & $23(12.6 \%)$ & 0.17 \\
\hline Hypertension & $7(11.5 \%)$ & $34(19.5 \%)$ & 0.15 \\
\hline Coronary artery disease & $8(13.1 \%)$ & $36(20.7 \%)$ & 0.19 \\
\hline Congestive heart failure & $12(19.7 \%)$ & $8(4.6 \%)$ & 0.001 \\
\hline Cerebral vascular accident & 7 (I I.5\%) & $18(10.3 \%)$ & 0.80 \\
\hline Peripheral vascular disease & $12(19.7 \%)$ & $4 I(23.6 \%)$ & 0.53 \\
\hline Cancer (solid tumors) & $9(14.8 \%)$ & $5(2.9 \%)$ & 0.001 \\
\hline \multicolumn{4}{|l|}{ Medications } \\
\hline Angiotensin-converting enzyme inhibitor & $23(37.7 \%)$ & $57(32.8 \%)$ & 0.48 \\
\hline Angiotensin receptor blockers & $12(19.7 \%)$ & $26(14.9 \%)$ & 0.38 \\
\hline Non-steroidal anti-inflammatory drugs & $5(8.2 \%)$ & $3(1.7 \%)$ & 0.01 \\
\hline Contrast & $12(19.7 \%)$ & $34(19.5 \%)$ & 0.98 \\
\hline Baseline creatinine, mean \pm SD $(\mu \mathrm{mol} / \mathrm{L})$ & I34.7 (88.9) & I35.I (III.4) & 0.98 \\
\hline Mean baseline eGFR (by CKD-EPI) \pm SD & $59.8( \pm 27.3)$ & $60.4( \pm 26.9)$ & 0.41 \\
\hline
\end{tabular}

Abbreviations: AKI, acute kidney injury; CKD-EPI, The Chronic Kidney Disease Epidemiology Collaboration; eGFR, estimated glomerular filtration rate. 
Looking at the comorbidities of our patients in the study, diabetes and hypertension were the major two; although the incidence was slightly low with $14.5 \%$ and $17.5 \%$ of patients affected, respectively. This may be explained by the higher cardiac mortality of older patients with the heavy burden of comorbidities such as diabetes mellitus, preventing them from reaching their $90 \mathrm{~s}^{17}$

It is well known that patients with cancer are at increased risk for AKI; that may be related to the direct effect of the cancer on the kidney, related to the metabolic derangement especially hypercalcemia, drug toxicity, sepsis, or other related factors. Old age was also shown to be a risk factor for AKI. ${ }^{18,19}$ In accordance, current results showed that cancer had a statistically significant impact on kidney function. Heart failure is another risk factor for renal dysfunction through hemodynamic changes, reduced renal perfusion, and neurohumoral mechanisms, ${ }^{20}$ where results of the current study showed that patients with congestive heart failure are at increased risk for AKI $(P=0.001){ }^{21,22}$

Regarding the hospital admissions, uncontrolled diabetes and complications associated with hypertension were the main two causes. Cardiac events and ACS were other major causes for admission in $14.2 \%$. Receiving full management with catheterization, stenting, ${ }^{23}$ and cardiac surgery ${ }^{24,25}$ is considered debatable for older individuals, even among members of the medical field who commonly treat nonagenarians.

Falling is another big concern with the nonagenarian population as most individuals in this age group have frailty, movement limitations, cognitive dysfunction, and malnutrition, which will increase the risk of falling. ${ }^{26-29}$ Unfortunately, as this study is a retrospective one, we could not do an analysis to determine a correlation between falling and cognitive dysfunction or frailty as a cause. Another issue that we could not assess in the current analysis was the correlation between the socioeconomic status of nonagenarian patients and their risk for morbidity and mortality. ${ }^{30,31}$

Approximately a quarter of the patients enrolled in this study were diagnosed with AKI, which is a relatively high proportion. In addition, those patients had several complications. For example, patients with AKI had higher overall mortality $^{32}$ and longer hospital stays (almost double) compared to patients without AKI. Previous studies have shown that rehospitalization is also more common in older individuals and is associated with high medical costs and mortality. ${ }^{32,33}$ The majority of patients with AKI were in Stage I (66.1\%). This finding supports with results of a large population-based study done in China that used the AKIN criteria. ${ }^{34}$ Frailty itself in nonagenarians can increase the risk for AKI and mortality. ${ }^{35}$ In patients of the current study, congestive heart failure was associated with AKI and longer hospital stays, which correlated with results of previous studies..$^{21,22}$

In severe AKI, the need for renal replacement therapy, including dialysis, is higher and may increase in-hospital stay and mortality. In fact, patients with severe AKI (Stage III AKIN) usually are sicker and it is well known that they will need dialysis more than less sick patients (Stages I and II AKIN), and subsequently they will need more time to recover and will remain longer in hospital. In that respect, a significant number of affected patients may require chronic dialysis, ${ }^{36}$ and in the current study, 61 patients $(25.9 \%)$ developed AKI, which is slightly higher than the incidence, $21.6 \%$, found in other studies. ${ }^{37}$ In current assessment of mortality rates in patients with AKI, it was found that $58 \%$ of current patient cohort died during the study period, which is again slightly higher than rates found in other studies. ${ }^{37}$ Having indicated these differences, a careful attention should be made while interpreting and comparing results among the multiple published studies as these studies were done at different geographical areas, and the classification used to identify AKI is different among different studies.

After 1-year follow-up, patients with AKI were more likely to have higher creatinine than patients who were discharged without AKI. However, due to a relatively small number of patients in the current study, the risk for CKD development was not evaluated. Still, other studies showed that having AKI will increase risk for later CKD. ${ }^{38}$

Among patients with AKI, only $11.9 \%$ of patients underwent dialysis, which could be related to patient and family apprehension toward dialysis treatment, knowing its possible complications. Physicians, as well, sometimes prefer a more conservative approach..$^{39,40}$ Overall, due to the growth of population, the number of nonagenarians initiating dialysis has increased yet due to other comorbidities and functional decline, survival has not improved significantly. ${ }^{41}$

One limitation of this study is its retrospective design consisting of a relatively small number of patients. Though we were able to establish some conclusions regarding AKI incidence, risk factors, and outcomes in nonagenarian patients, this design did not allow us to identify a correlation between cognitive function, frailty, falling risks in patients, and their survival with or without AKI. In the future, cooperation with other centers in developing comprehensive studies consisting of larger patient cohorts will facilitate a more in-depth evaluation of the risks for 
AKI and outcomes in nonagenarians including critically ill patients (intensive care unit and cardiac/coronary care unit), surgical patients, and patients with sepsis, and including comprehensive assessment patients' medications, namely antibiotics and chemotherapeutic agents.

\section{Conclusion}

Nonagenarians are a growing population in need of their own approach for medical evaluations and treatment. This study showed that AKI is high among nonagenarians, and that it was associated with increased length of hospital stays and increased risk for mortality. Meeting distinct medical needs of this population will help reduce mortality and AKI risks.

\section{Acknowledgment}

This research was funded by Jordan University of Science and Technology/Deanship of Research

\section{Disclosure}

The authors report no conflicts of interest in this work.

\section{References}

1. Manton KG, Vaupel JW. Survival after the age of 80 in the United States, Sweden, France, England, and Japan. $N$ Engl J Med. 1995;333(18):1232-1235.

2. Randall GK, Martin P, Bishop AJ, Poon LW, Johnson MA. Age differences and changes in resources essential to aging well: a comparison of sexagenarians, octogenarians, and centenarians. Curr Gerontol Geriatr Res. 2011;2011:357896.

3. Santoni G, Angleman S, Welmer AK, Mangialasche F, Marengoni A, Fratiglioni L. Age-related variation in health status after age 60. PLoS One. 2015;10(3):e0120077.

4. Oweis AO, Alshelleh SA. Incidence and outcomes of acute kidney injury in octogenarians in Jordan. BMC Res Notes. 2018;11(1):279.

5. Glassock RJ, Rule AD. Aging and the kidneys: anatomy, physiology and consequences for defining chronic kidney disease. Nephron. 2016;134(1):25-29.

6. Glassock RJ, Rule AD. The implications of anatomical and functional changes of the aging kidney: with an emphasis on the glomeruli. Kidney Int. 2012;82(3):270-277.

7. Chertow GM, Burdick E, Honour M, Bonventre JV, Bates DW. Acute kidney injury, mortality, length of stay, and costs in hospitalized patients. J Am Soc Nephrol. 2005;16(11):3365-3370.

8. Xue JL, Daniels F, Star RA, et al. Incidence and mortality of acute renal failure in medicare beneficiaries, 1992 to 2001. J Am Soc Nephrol. 2006;17(4):1135-1142.

9. Musso CG, Oreopoulos DG. Aging and physiological changes of the kidneys including changes in glomerular filtration rate. Nephron Physiol. 2011;119(Suppl 1):p1-p5.

10. Gong Y, Zhang F, Ding F, Gu Y. Elderly patients with acute kidney injury (AKI): clinical features and risk factors for mortality. Arch Gerontol Geriatr. 2012;54(2):e47-e51.

11. Turgutalp K, Bardak S, Horoz M, Helvacı I, Demir S, Kiykim AA. Clinical outcomes of acute kidney injury developing outside the hospital in elderly. Int Urol Nephrol. 2017;49(1):113-121.

12. Ge S, Nie S, Liu Z, et al. Epidemiology and outcomes of acute kidney injury in elderly Chinese patients: a subgroup analysis from the $\mathrm{EACH}$ study. BMC Nephrol. 2016;17(1):136.
13. Chao CT, Tsai HB, Wu CY, et al. Cumulative cardiovascular polypharmacy is associated with the risk of acute kidney injury in elderly patients. Medicine (Baltimore). 2015;94(31):e1251.

14. Zeng X, McMahon GM, Brunelli SM, Bates DW, Waikar SS. Incidence, outcomes, and comparisons across definitions of AKI in hospitalized individuals. Clin J Am Soc Nephrol. 2014;9(1):12-20.

15. Goldman DP, Cutler D, Rowe JW, et al. Substantial health and economic returns from delayed aging may warrant a new focus for medical research. Health Aff (Millwood). 2013;32(10):1698-1705.

16. Burch JB, Augustine AD, Frieden LA, et al. Advances in geroscience: impact on healthspan and chronic disease. J Gerontol A Biol Sci Med Sci. 2014;69(Suppl 1):S1-S3.

17. Huang ES, Laiteerapong N, Liu JY, John PM, Moffet HH, Karter AJ. Rates of complications and mortality in older patients with diabetes mellitus: the diabetes and aging study. JAMA Intern Med. 2014;174(2): 251-258.

18. Perazella MA, Rosner MH. Acute kidney injury in patients with cancer. Oncology (Williston Park). 2018;32(7):351-359.

19. Rosner MH, Perazella MA. Acute kidney injury in patients with cancer. N Engl J Med. 2017;376(18):1770-1781.

20. Han SW, Ryu KH. Renal dysfunction in acute heart failure. Korean Circ J. 2011;41(10):565-574.

21. Chao CT, Lin YF, Tsai HB, et al; HINT Study Group. In nonagenarians, acute kidney injury predicts in-hospital mortality, while heart failure predicts hospital length of stay. PLoS One. 2013;8(11):e77929.

22. Formiga F, Ferrer A, Mascaró J, Ruiz D, Olmedo C, Pujol R. Predictive items of one-year mortality in nonagenarians. The NonaSantfeliu Study. Aging Clin Exp Res. 2007;19(4):265-268.

23. Lebude B, Fischman D, Savage M, et al. Safety, effectiveness, and outcomes of cardiac catheterization in nonagenarians. Am J Cardiol. 2012;110(9):1231-1233.

24. Davis JP, Lapar DJ, Crosby IK, et al. Nonagenarians undergoing cardiac surgery. J Card Surg. 2014;29(5):600-604.

25. Pelavski AD, Lacasta A, de Miguel M, Rochera MI, Roca M. Mortality and surgical risk assessment among the extreme old undergoing emergency surgery. Am J Surg. 2013;205(1):58-63.

26. Formiga F, Ferrer A, Chivite D, Rubio-Rivas M, Cuerpo S, Pujol R. Predictors of long-term survival in nonagenarians: the NonaSantfeliu study. Age Ageing. 2011;40(1):111-116.

27. Thinggaard M, McGue M, Jeune B, Osler M, Vaupel JW, Christensen K. Survival prognosis in very old adults. J Am Geriatr Soc. 2016;64(1):81-88

28. Socorro García A, de La Puente M, Perdomo B, López Pardo P, Baztán JJ. Functional status and mortality at month and year in nonagenarians hospitalized due to acute medical illness. Eur J Intern Med. 2015;26(9):705-708.

29. Hwabejire JO, Kaafarani HM, Lee J, et al. Patterns of injury, outcomes, and predictors of in-hospital and 1-year mortality in nonagenarian and centenarian trauma patients. JAMA Surg. 2014;149(10): 1054-1059.

30. Enroth L, Raitanen J, Hervonen A, Nosraty L, Jylhä M. Is socioeconomic status a predictor of mortality in nonagenarians? The vitality $90+$ study. Age Ageing. 2015;44(1):123-129.

31. Nybo H, Petersen HC, Gaist D, et al. Predictors of mortality in 2,249 nonagenarians - the Danish 1905-Cohort Survey. J Am Geriatr Soc. 2003;51(10):1365-1373.

32. Chao CT, Tsai HB, Wu CY, et al. The severity of initial acute kidney injury at admission of geriatric patients significantly correlates with subsequent in-hospital complications. Sci Rep. 2015;5:13925.

33. Doyle JF, Forni LG. Acute kidney injury: short-term and long-term effects. Crit Care. 2016;20(1):188.

34. Wei Q, Liu H, Tu Y, et al. The characteristics and mortality risk factors for acute kidney injury in different age groups in China - a cross sectional study. Ren Fail. 2016;38(9):1413-1417.

35. Baek SH, Lee SW, Kim SW, et al. Frailty as a predictor of acute kidney injury in hospitalized elderly patients: a single center, retrospective cohort study. PLoS One. 2016;11(6):e0156444. 
36. Gautam SC, Brooks CH, Balogun RA, Xin W, Ma JZ, Abdel-Rahman EM. Predictors and outcomes of post-hospitalization dialysis dependent acute kidney injury. Nephron. 2015;131(3):185-190.

37. Susantitaphong P, Cruz DN, Cerda J, et al. World incidence of AKI: a meta-analysis. Clin J Am Soc Nephrol. 2013;8(9):1482-1493.

38. Chawla LS, Eggers PW, Star RA, Kimmel PL. Acute kidney injury and chronic kidney disease as interconnected syndromes. $N$ Engl J Med. 2014;371(1):58-66.
39. Kooman JP, Cornelis T, van der Sande FM, Leunissen KM. Renal replacement therapy in geriatric end-stage renal disease patients: a clinical approach. Blood Purif. 2012;33(1-3):171-176.

40. Jassal SV, Watson D. Dialysis in late life: benefit or burden. Clin J Am Soc Nephrol. 2009;4(12):2008-2012.

41. Kurella M, Covinsky KE, Collins AJ, Chertow GM. Octogenarians and nonagenarians starting dialysis in the United States. Ann Intern Med. 2007;146(3):177-183.

\section{Publish your work in this journal}

The International Journal of Nephrology and Renovascular Disease is an international, peer-reviewed open access journal focusing on the pathophysiology of the kidney and vascular supply. Epidemiology, screening, diagnosis, and treatment interventions are covered as well as basic science, biochemical and immunological studies. The manuscript management system is completely online and includes a very quick and fair peer-review system, which is all easy to use. Visit http://www. dovepress.com/testimonials.php to read real quotes from published authors.

Submit your manuscript here: https://www.dovepress.com/international-journal-of-nephrology-and-renovascular-disease-journal 